\title{
Treatment of iatrogenic acute aortic type A aortic dissection complicating transcatheter aortic valve insertion: A case report
}

\author{
Busra Cangut, MD, and Kevin L. Greason, MD, Rochester, Minn
}

\footnotetext{
From the Department of Cardiovascular Surgery, Mayo Clinic, Rochester, Minn. Disclosures: The authors reported no conflicts of interest.

The Journal policy requires editors and reviewers to disclose conflicts of interest and to decline handling or reviewing manuscripts for which they may have a conflict of interest. The editors and reviewers of this article have no conflicts of interest.

Received for publication July 6, 2020; revisions received July 6, 2020; accepted for publication July 28, 2020; available ahead of print Aug 11, 2020.

Address for reprints: Kevin L. Greason, MD, Division of Cardiovascular Surgery, Mayo Clinic, 200 First St, Southwest, Rochester, MN 55905 (E-mail: greason.kevin@mayo.edu).

JTCVS Techniques 2020;3:68-9

2666-2507

Copyright (c) 2020 The Authors. Published by Elsevier Inc. on behalf of The American Association for Thoracic Surgery. This is an open access article under the CC BY-NC-ND license (http://creativecommons.org/licenses/bync-nd/4.0/).

https://doi.org/10.1016/j.xjtc.2020.07.023
}

A 79-year-old frail female patient with scleroderma presented with symptomatic severe aortic stenosis. The aortic valve annulus diameter was $21 \mathrm{~mm}$, and perimeter was $66 \mathrm{~mm}$. She was an appropriate candidate for the transfemoral 26-mm Evolut valve (Medtronic, Dublin, Ireland). The procedure was performed in the operating room with the patient under general endotracheal anesthesia with transesophageal echocardiography.

Percutaneous access was obtained of both femoral arteries. A stable stiff wire platform was established across the patient's native aortic valve. Balloon aortic valvuloplasty was not done. The delivery device was inserted under fluoroscopic guidance. It seemed to hang up right at the aortic arch. The device was subsequently pulled back, rotated, redirected, and then it passed through the aortic arch without difficulty. The valve was partially deployed in the standard fashion to a depth of $4 \mathrm{~mm}$. Hemodynamics remained stable.

Echocardiography demonstrated trivial paravalvular regurgitation but also acute ascending aortic dissection. The valve was completely deployed, and the delivery device was removed. An 18-French arterial cannula was placed in the right femoral artery.

A median sternotomy was completed. A 2-stage venous cannula and a left ventricular vent were placed. The patient was placed on cardiopulmonary bypass and cooled to $18^{\circ} \mathrm{C}$. Deep hypothermic circulatory arrest was initiated for $24 \mathrm{mi}-$ nutes. The ascending aorta was resected from the innominate artery down to the level of the transcatheter valve. There was a small tear in the proximal descending thoracic aorta, which was left alone. There was no entry tear in the resected specimen.

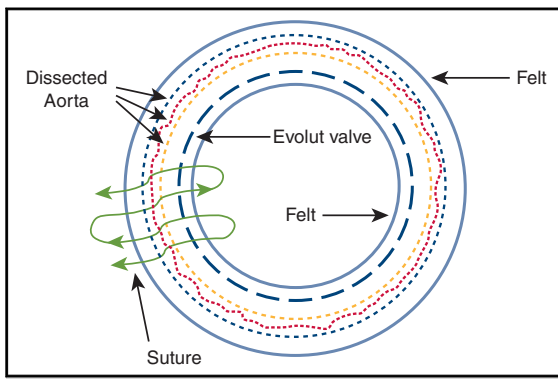

Felt sandwich of dissected aortic root and selfexpanding transcatheter aortic valve.

\section{CENTRAL MESSAGE}

This report describes use of a self-expanding transcatheter valve prosthesis in the repair of an iatrogenic acute ascending aortic dissection during transcatheter aortic valve insertion.

See Commentary on page 70.

Examination showed dissection of the aortic root without an entry tear. The coronary ostia were widely patent. The stent frame of the transcatheter valve was approximating the layers of the aorta. The root was repaired with surgical adhesive. A felt sandwich was created with the transcatheter

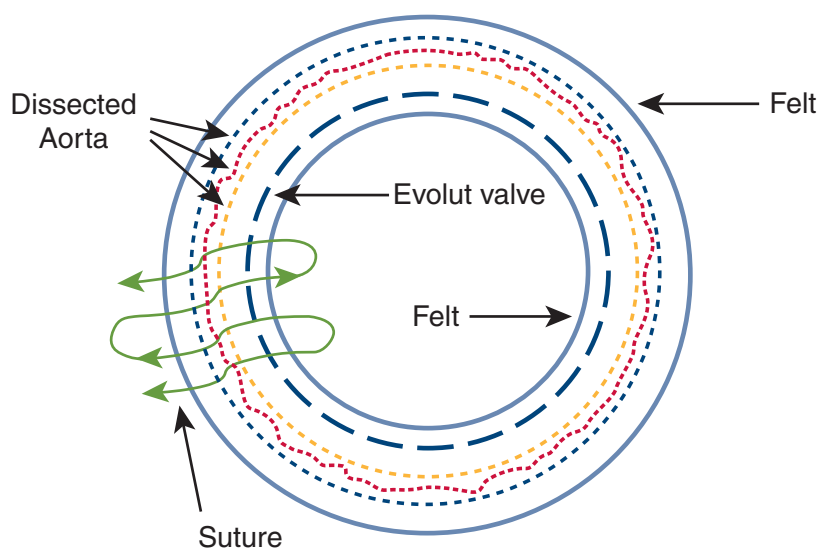

FIGURE 1. Felt sandwich of dissected aortic root and self-expanding transcatheter aortic valve. 


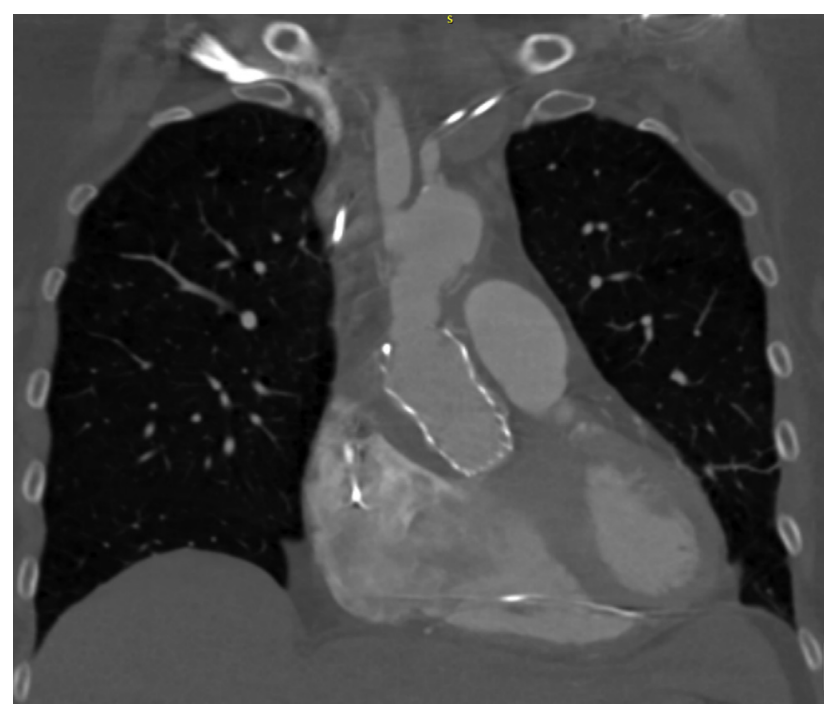

FIGURE 2. Coronal computed tomography image of repaired aortic root and replaced ascending aorta.

valve and continuous polypropylene suture (Figure 1). The ascending aorta was replaced with a 20-mm polyester graft. The aortic crossclamp was released after 93 minutes.

The patient was weaned from cardiopulmonary bypass without difficulty. Echocardiography demonstrated trivial paravalvular regurgitation and preserved ejection fraction.

The patient recovered well. She was discharged 7 days later. Echocardiography demonstrated a mean systolic aortic transvalvular gradient of $5 \mathrm{~mm} \mathrm{Hg}$, trivial paravalvular regurgitation, and no evidence of aortic root dissection. Computed tomography scan at discharge demonstrated no evidence of aortic root (Figure 2) or descending thoracic aorta dissection.

The patient was alive with New York Heart Association functional class III dyspnea at last follow-up 44 months after operation. Echocardiography demonstrated a mean systolic aortic transvalvular gradient of $7 \mathrm{~mm} \mathrm{Hg}$, trivial paravalvular regurgitation, and no evidence of aortic root dissection.

The patient gave informed consent to the publication of this case report.

\section{DISCUSSION}

Our patient experienced acute ascending aortic dissection, most likely during insertion of the delivery device across the aortic arch. It was by chance that the transcatheter valve had been partially deployed before the dissection was diagnosed. Because there was good position of the valve with minimal paravalvular regurgitation, we elected to complete deployment of the valve. This resulted in a competent aortic valve, which may have prevented lifethreatening acute aortic valve regurgitation.

It was also by chance that we noted the transcatheter selfexpanding stent frame was pushing out on the aorta in a sense obliterating the acute dissection. In our mind, this seemed like an ideal situation in which to apply surgical adhesive. The result was an acutely hemostatic and apparently durable reconstruction of the aortic root and valve. It is our sense that the alternative of transcatheter valve removal combined with standard root reconstruction and/or valve replacement techniques would have resulted in a more complex operation. Furthermore, we felt a total arch replacement was too aggressive for this elderly, frail woman.

The sequence of events in this case probably contributed to the positive outcome. It is unknown whether a transcatheter aortic valve has been successfully inserted in the setting of acute ascending aortic dissection and significant native aortic valve regurgitation (PubMed search completed April 14,2020 ), although there is a previous report of selfexpanding uncovered stent insertion to treat acute ascending aortic dissection after TAVI. ${ }^{2}$

\section{CONCLUSIONS}

This case report describes successful repair of an acute ascending aortic dissection using standard open operative techniques combined with self-expanding transcatheter aortic valve insertion.

\section{References}

1. Kalra A, Reardon M, Barker C, Kleiman N, Reyes M. Chapter 11: Step-by-step guide: transfemoral Corevalve Evolut TAVR. Available at: https://www.acc.org/ $\sim /$ media/Non-Clinical/Files-PDFs-Excel-MS-Word-etc/Membership/TAVR-Hand book/Chapter-11-Step-by-step-guide-transfemoral-corevalve-evolut-TAVR-March2-2018.pdf. Accessed July 6, 2020.

2. D'Ancona G, Kische S, Dissman M, Pasic M, Mladenow A, Ince H. Transfemoral uncovered stent to treat iatrogenic type A dissection during transcatheter aortic valve implantation. Eur Heart J. 2015;36:187. 